\title{
Influence of Sulphite on the Drying Kinetics of Pumpkin Fruit Slices
}

\section{Comfort Mkpentseen Bunde-Tsegba*, Charles Chukwuma Ariahu, Bibiana Dooshima Igbabul, Joseph Oneh Abu}

Department of Food Science and Technology, University of Agriculture, Makurdi, Nigeria

Email address:

bundecomfort $a$ gmail.com (C. M. Bunde-Tsegba)

${ }^{*}$ Corresponding author

\section{To cite this article:}

Comfort Mkpentseen Bunde-Tsegba, Charles Chukwuma Ariahu, Bibiana Dooshima Igbabul, Joseph Oneh Abu. Influence of Sulphite on the Drying Kinetics of Pumpkin Fruit Slices. World Journal of Food Science and Technology. Vol. 3, No. 3, 2019, pp. 32-39.

doi: $10.11648 /$ j.wjfst.20190303.11

Received: July 30, 2019; Accepted: October 26, 2019; Published: December 2, 2019

\begin{abstract}
Drying kinetics, of pumpkin fruit slices as influenced by sulphiting, was investigated. Pumpkin fruits, were sulphited at $0,1.0,1.5,2.0$ and $2.5 \%$ to obtain $4 \mathrm{~mm}$ thick (P0, 4; P1, 4; P1.5 4; P2, 4; P2.5, 4 - and 5 mm samples (P0, 5; P1, 5; P1.5, 5; P2, 5; P2.5, 5 respectively). Samples were dried at $60,65,70,75$ and $80^{\circ} \mathrm{C}$ at an air velocity of $1.53 \mathrm{~m} / \mathrm{s}$. Drying was carried out to constant moisture. Samples were screened using descriptive sensory evaluation to obtain samples P1, 4 and $\mathrm{P} 2,5$ each dried at $75^{\circ} \mathrm{C}$ as the best samples for $4 \mathrm{~mm}$ and $5 \mathrm{~mm}$ respectively. Drying curves, moisture diffusitivity, activation energy, drying time and rehydration capacity were determined. The drying curves obtained showed results for a short constant rate followed by a falling rate period. The effective moisture diffusivity varied from $6.235 \times 10^{-11}$ to $12.808 \times 10^{-11} \mathrm{~m}^{2} / \mathrm{s}$ for the 4 $\mathrm{mm}$ and $9.046 \times 10^{-11}$ to $21.330 \times 10^{-11} \mathrm{~m}^{2} / \mathrm{s}$ for the $5 \mathrm{~mm}$ samples. Activation energy obtained for P0, 4; P1, 4; P0, 5 and P2, 5 were $31.342,32.292,31.525$ and $29.88 \mathrm{~kJ} / \mathrm{mol}$. respectively. Sulphiting reduced drying time at $1 \%$ level from 16.5 to 15.2 hours for the $4 \mathrm{~mm}$ sample and 17.8 to 16.9 hours at $2 \%$ level of sulphiting for the $5 \mathrm{~mm}$. Sulphite treatment reduced rehydration capacity significantly at $p>0.05$. This study implies that the parameter which governed the internal transfer of moisture was moisture diffusion.
\end{abstract}

Keywords: Drying, Sulphite, Diffusitivity, Rehydration and Pumpkin

\section{Introduction}

Cucurbita pepo is known as pumpkin in English, elegede in Yoruba (Nigeria), calbaza, in Mexico and furum in Tiv (Nigeria). Cucurbita pepo is a herb grown for its fruits and edible seeds [1]. Pumpkin belongs to the family of cucurbitaceae which includes; cucumbers, melons, squash and gourds [2]. Cultivated pumpkins are believed to have originated from Central Africa, as far back as $550 \mathrm{BC}$ and are now widely grown all over the world. Sulphiting of fruits and vegetables has been used in inhibiting enzymatic and nonenzymatic browning [3].

Fruits and seeds of pumpkin are mostly used for culinary and medicinal purposes [4]. In Nigeria, pumpkin (fruit) is commonly consumed fresh. The succulent fruits are boiled and taken alone or mashed with boiled yam to form potage or the fruits are processed by peeling, removing the seeds, slicing and sun-drying. The dried slices are prepared into soup in combination with ground melon seeds (egusi) or beniseed as a delicacy. Pumpkin fruit has antioxidant capacities as a result of its carotenoids content. Carotenoids in terms of human health reduce cataracts and macular degeneration [5]. Carotenoids are the natural plant pigments which are responsible for the orange colour of pumpkins. It is considered to be a good source of carotenoids, and a very rich source of carotene [6]. The main nutrient is beta carotene, which generates vitamin $\mathrm{A}$ in the body. The major caroteneoids in pumpkin fruits include; $\beta$-carotene, $\alpha$ carotene, lutein, lycopene, cryptozanthin and zeazanthin [7]. Pumpkin fruit is also a valuable source of vitamins such as vitamin $\mathrm{B}_{1}$ (thiamine), vitamin $\mathrm{B}_{2}$ (riboflavin), vitamin $\mathrm{B}_{3}$ (niacin), vitamin $\mathrm{B}_{5}$ (pantothenic acid), vitamin $\mathrm{B}_{6}$ (pyridoxine), vitamin $\mathrm{B}_{9}$ (folic acid). However, the perishable 
nature of this fruit limits its utilization.

Pumpkin fruits are very difficult to preserve. Freezing results to 'freeze burn', while refrigerating only keeps for a few days. The only method of preservation that is suitable is sun-drying. This is only common in the tropics and sub-tropics. In addition, sun-drying has a lot of limitations [8]. Dehydrated food products according to Serenet et al, are hygroscopic, therefore, needs adequate drying [9]. Pumpkin fruit slices as a semi-finished fruit product needs to be crispy, in addition, have the potentials to reconstitute as close to the fresh form as possible when immersed in water

Studies by Gujral et al, Ramallo and Mascherni revealed that drying is the most important process of preserving fruits and vegetables $[10,11]$. Literature report indicates that a host of these drying processes employ convective hot air drying and about $85 \%$ of industrial dryers are convective hot air types $[12,13]$. According to Vazquez-Vila, the removal of moisture prevents the growth and reproduction of microorganisms causing decay and inhibits many of the moisture-mediated deteriorative reactions. It brings about substantial reduction in weight and volume, thereby, minimizing packaging, storage, transportation and distribution cost. In addition, drying aids storability of the product under ambient conditions [14].

Sun drying has been used to dry fruits and vegetables in tropical and subtropical regions. Studies by, Prajapati et al revealed that the quality of fruits and vegetables dried by conventional sun drying technique has to be replaced with mechanical drying (dehydration) which is assumed to produce better and consistent quality fruits and vegetable products, taking less time and minimizing microbial spoilage and chemical deterioration, thereby, alleviating the problem of fruits and vegetable losses [15]. Nguyen and Price revealed that, use of hot air drying as an alternative drying method both decreases the drying time and improve the quality of the final product in addition to low cost [16]. Mechanical drying is therefore used for various foods such as banana. Several researchers used it to dry srawberry, steamed glutinous rice, oyster mushroom and coffee as well as combing with microwave to dry brown rice $[17,18,19,20,21]$. In dehydration process, hot air heats the samples to remove the moisture. In high moisture foods such as fruits and vegetables, the drying air removes water from the food surface by evaporation for the fact that the available water in the food sample under drying occur at a very high water activity. The controlling factor of the drying process at this point is the heat supplied by the drying air to the drying food sample. This stage of drying process is referred to as the constant rate period [16]. The removal of water from food products depends on not only drying temperature but also slice thickness, drying conditions as well as sample geometry $[22,23,16]$. When the water activity of the available water on the surface of a drying food sample drops, moisture diffuses from inside the food material to the surface as a result of partial pressure or concentration gradient. The controlling factor of the drying processes (evaporation) then changes to the rate at which water travels through the thickness of the food to the surface. This marks the beginning of the falling rate period. Several works have been carried out on drying kinetics of different species of pumpkin fruits using variable slice thicknesses [24].

\section{Effective Moisture Diffusitivity (Deff) and Activation} Energy (Ea)

In drying kinetics, moisture can be expressed in terms of moisture ratio which is the ratio of the removed water to the removable water in a food substance under drying. This is expressed as:

$$
\mathrm{MR}=\frac{M_{t}-M_{e}}{M_{i}-M_{e}}
$$

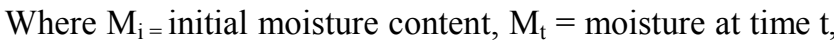
$\mathrm{M}_{\mathrm{e}}=$ equilibrium moisture content. Drying of fruits and vegetables is considered in the falling rate period [25]. Ficks' diffusion equation was used by Jittanit and Arumuganathan et al to model the drying behaviour of food systems since drying in the falling rate period is controlled by internal moisture diffusion of the food material [26, 27]. Effective moisture diffusitivity represents the conductive term of all moisture transfer mechanisms. Investigation by Roberts et al revealed that, based on assumptions of initial uniform moisture content, negligible external resistance to mass transfer, negligible temperature gradients, negligible shrinkage during drying and constant diffusitivity coefficient, the analytical solution of diffusion equation is given for an infinite slab as:

$$
\stackrel{M R}{\longleftarrow}=\frac{M_{i}-M_{e}}{M_{o}-M_{e}}=\frac{8}{\pi^{2}} \exp \left(-\pi^{2} \frac{\text { Defft }}{L^{2}}\right)
$$

Where $\mathrm{MR}=$ unaccomplished moisture or moisture ratio. $\mathrm{Mi}=$ initial moisture content, $\mathrm{M}_{\mathrm{t}}=$ moisture at time $\mathrm{t}, \mathrm{Me}=$ equilibrium moisture content. Deff $=$ effective moisture diffusitivity $\left(\mathrm{m}^{2} / \mathrm{s}\right), \mathrm{L}=$ thickness of slab before drying, $\mathrm{t}=$ drying time [28].

Deff is usually derived from experimental drying curves by plotting experimental values of $\operatorname{lnMR}$ versus time from equation (1) which gives a straight line graph with a slope of:

$$
\text { Slope }=\frac{\pi^{2} \text { Deff }}{L^{2}}
$$

Temperature dependence of diffusitivity has been shown to follow an Arrehnius relationship according to works done by [29]. The relationship is represented as;

$$
D_{e f f}=D_{o} \exp \left(\frac{E_{a}}{R T}\right)
$$

Where, $\mathrm{D}_{\mathrm{o}}=$ the pre-exponential factor of the Arrehnius equation $\left(\mathrm{m}^{2} / \mathrm{s}\right), \mathrm{E}_{\mathrm{a}}=$ activation energy $(\mathrm{kJ} / \mathrm{mol} \mathrm{K})$ and $\mathrm{T}=$ drying temperature $\left({ }^{\circ} \mathrm{C}\right)$. The activation energy is calculated by plotting $\operatorname{lnDeff}$ versus the reciprocal of the absolute temperature. Using equation (1) and (3), Despite the vast 
research on the drying of pumpkin fruit slices, there is scarce literature on the drying behaviour of pumpkin (Cucurbita pepo) fruit slices in relation to sulphiting. This study aims at investigating the influence of sulphite on the internal moisture transfer mechanism during drying of pumpkin fruit slices, the drying time of fresh slices and reconstitution capacity of the dried pumpkin slices.

\section{Materials and Methods}

\subsection{Raw Material}

About $5 \mathrm{~kg}$ of matured pumpkin fruits of average moisture content $94.4 \% \pm 0.21$ and $3.8^{\circ} \pm 0.1$ Brix were harvested the same time from a private garden. These two parameters were used as indices for uniform maturity of the pumpkin fruits. The fruits were washed using tap water to remove soil and other debris. They were then kept in an incubated refrigerator at $4^{\circ} \mathrm{C}$ for temperature to equilibrate before use for the processing operations. Sodium metabisulphite $(250 \mathrm{~g})$ of laboratory grade was obtained from a chemical shop in Makurdi Benue state of Nigeria.

\subsection{Sample Preparation}

Pumpkin fruits were peeled using a stainless steel knife. The pulps of the fruits with seeds were removed and the thick mesocarp sliced in to pieces of $4 \mathrm{~mm}$ and $5 \mathrm{~mm}$ thickness with the aid of a digital vernier calliper. The choice of thinness was to simulate market samples based on the information obtained from the local producers. The sliced fruits were weighed in five portions of $50 \mathrm{~g}$ for each of the two sizes. Sodium metabisulphite solutions of 1.0, 1.5, 2.0 and $2.5 \%$ were prepared and placed in $500 \mathrm{ml}$ beakers. To each concentration of salt, $50 \mathrm{~g}$ of $4 \mathrm{~mm}$ and $5 \mathrm{~mm}$ pumpkin fruit slices each were soaked in the prepared concentrations of sodium metabisulphate for 5 minutes to obtain four samples for the $4 \mathrm{~mm}$ size namely; P1, 4; P1.5, 4; P2, 4; P2.5 4 and a non sulphited sample P0, 4 which was the control. Same thing was done for the $5 \mathrm{~mm}$ size of slices to obtain samples P1, 5; P1.5, 5; P2, 5; P2.5, 5 and a non sulphited sample P0, 5 was used as the control. The sample slices were removed, allowed to drain and arranged on non- perforated trays in a single uniformly thin layer within a hot air tray dryer so that hot air passed around one side of the slices. This was done for the controls as well which were soaked in water containing no salt as described by [30, 31]. Drying was carried out at $60,65,70,75$, and $80^{\circ} \mathrm{C}$ at a drying air velocity of $1.53 \mathrm{~m} / \mathrm{s}$, during which weights of the samples were taken at the intervals of 30 minutes until constant weight of sample was achieved. Samples were subjected to descriptive sensory evaluation to obtain sample $\mathrm{P} 1,4$ dried at $75^{\circ} \mathrm{C}$ as the best among $4 \mathrm{~mm}$ thick samples and $\mathrm{P} 2,5$ dried at $75^{\circ} \mathrm{C}$ as the best among $5 \mathrm{~mm}$ thick samples. Subsequent analysis were determined on these samples and their non sulphited counterparts (controls)

\subsection{Drying Procedure}

Moisture content (\%) of samples was determined by material balance using data on weights generated during the drying process of the samples. Drying curves were drawn by plotting values of moisture ratio versus drying time as presented in Figure 1. Equilibrium moisture content $\left(\mathrm{M}_{\mathrm{e}}\right)$ values were predicted graphically by plotting rate of drying $(\mathrm{dx} / \mathrm{dt})$ values of each sample against moisture content at a given temperature. $\mathrm{M}_{\mathrm{e}}$ values were considered as the point where the $\mathrm{Y}$-axis cuts $\mathrm{X}$-axis. The ratio of the removed water to removable water in the sample known as moisture ratio (MR) was determined from equation. (1). Fick's unsteady state second law of diffusion equation (2) was used due to the long drying time to model all data as according to the method described by [24]. The effective moisture diffusitivity $\left(D_{\text {eff }}\right)$ was calculated from the slope of the curve plotted from linear values of moisture ratio (lnMR) versus drying time $(t)$ as given in equation (3) and the results were presented in Table 1. Activation energy $\left(E_{a}\right)$ for each sample was determined using the Arrhenius temperature dependence of $D_{\text {eff }}$ as given in equation (4). A plot of $\ln D_{\text {eff }}$ versus inverse of absolute temperature gave a slope from which $\left(\mathrm{E}_{\mathrm{a}}\right)$ was calculated as shown in Table 2. Drying time was estimated using Fick's diffusion model for an infinite slab as given in equation (1). Equilibrium moisture content $\left(\mathrm{M}_{\mathrm{e}}\right)$ values were predicted graphically by plotting rate of drying $(\mathrm{dx} / \mathrm{dt})$ values of each sample against moisture content at a given temperature. $M_{e}$ values were considered as the point where the $\mathrm{Y}$-axis cuts $\mathrm{X}$ axis. The result of drying time is presented in Table 3

\subsection{Rehydration Capacity}

Rehydration capacity of sulphited and dried pumpkin fruit slices was carried out with modifications according to the method described by [17]. In this method, $100 \mathrm{ml}$ distilled water was added to $250 \mathrm{ml}$ beaker and placed in a water bath at different rehydration temperatures of 30,60 and $80^{\circ} \mathrm{C}$ at a time. To each beaker at its given temperature, $10 \mathrm{~g}$ of each sample P0, 4, P1, 4, P0, 5 and P2, 5 were rehydrated lat a resident time of 15 minutes after which the slices were drained and reweighed. Rehydration capacity was calculated as:

$$
R C=\frac{\text { Weight of soaked sample }}{\text { Weight of dry sample }}
$$

The result of rehydration capacity is presented in Table 4 .

\section{Results and Discussion}

\subsection{Drying Kinetics}

The drying curves of pumpkin fruit slices as shown in (Figures 1 and 2). 

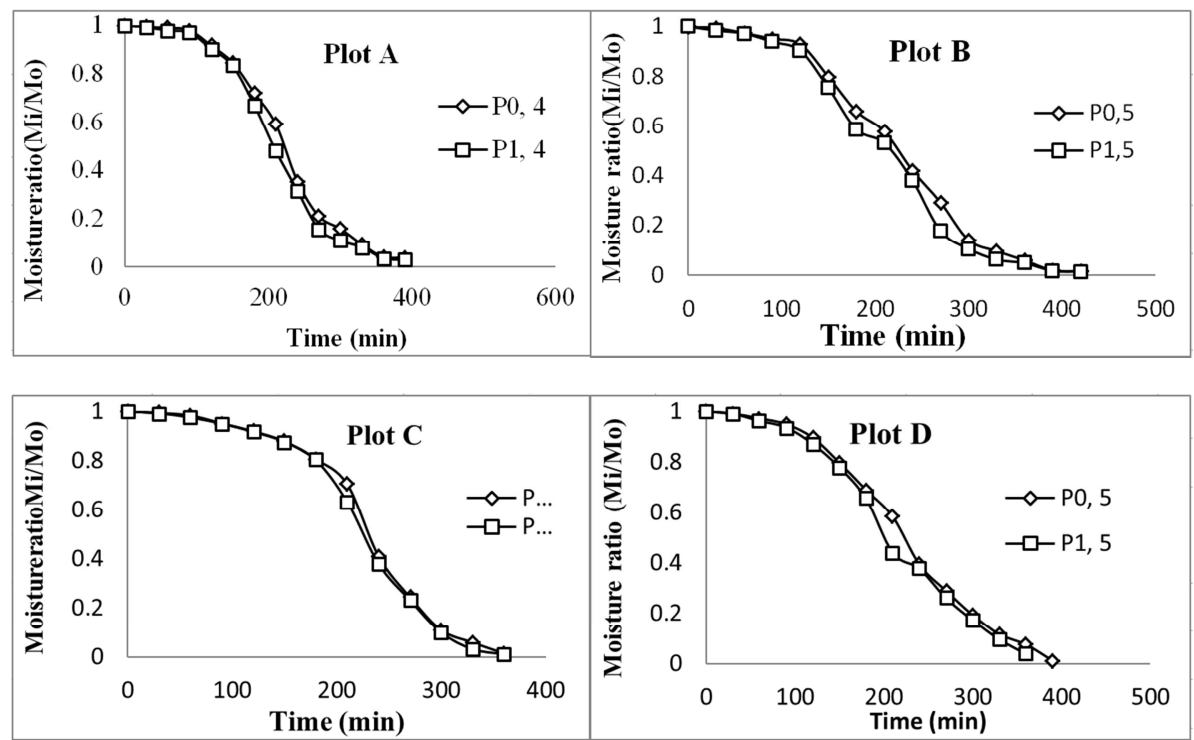

Figure 1. Effect of Sulphite on the Drying Behaviour of Pumpkin Fruit Slices of Thickness $4 \mathrm{~mm}$ (Plots $A$ and C) and $5 \mathrm{~mm}\left(\right.$ Plot B and D) at 60 and $65^{\circ} \mathrm{C}$.

This is in agreement with the findings of [17] that dried strawberry pre-treated with alkaline ethyloleate solution in a laboratory dryer at temperatures of 50,55 and $65^{\circ} \mathrm{C}$. This could be attributed to the high initial moisture content (94.4\%) of the pumpkin fruits. However, the falling rate dominated the drying process.

Drying predominantly followed a falling rate period. This was indicated by the presence of a short lived constant rate period in the early stage of drying. It can be inferred that drying occurred by evaporation of water at the surface of the pumpkin slices as a result of free water that was available at a very high water activity. When the water activity reduced, the constant rate ceased and a falling rate period began. This implies that, moisture transfer during the falling rate period was predominantly caused by liquid diffusion or capillary flow.
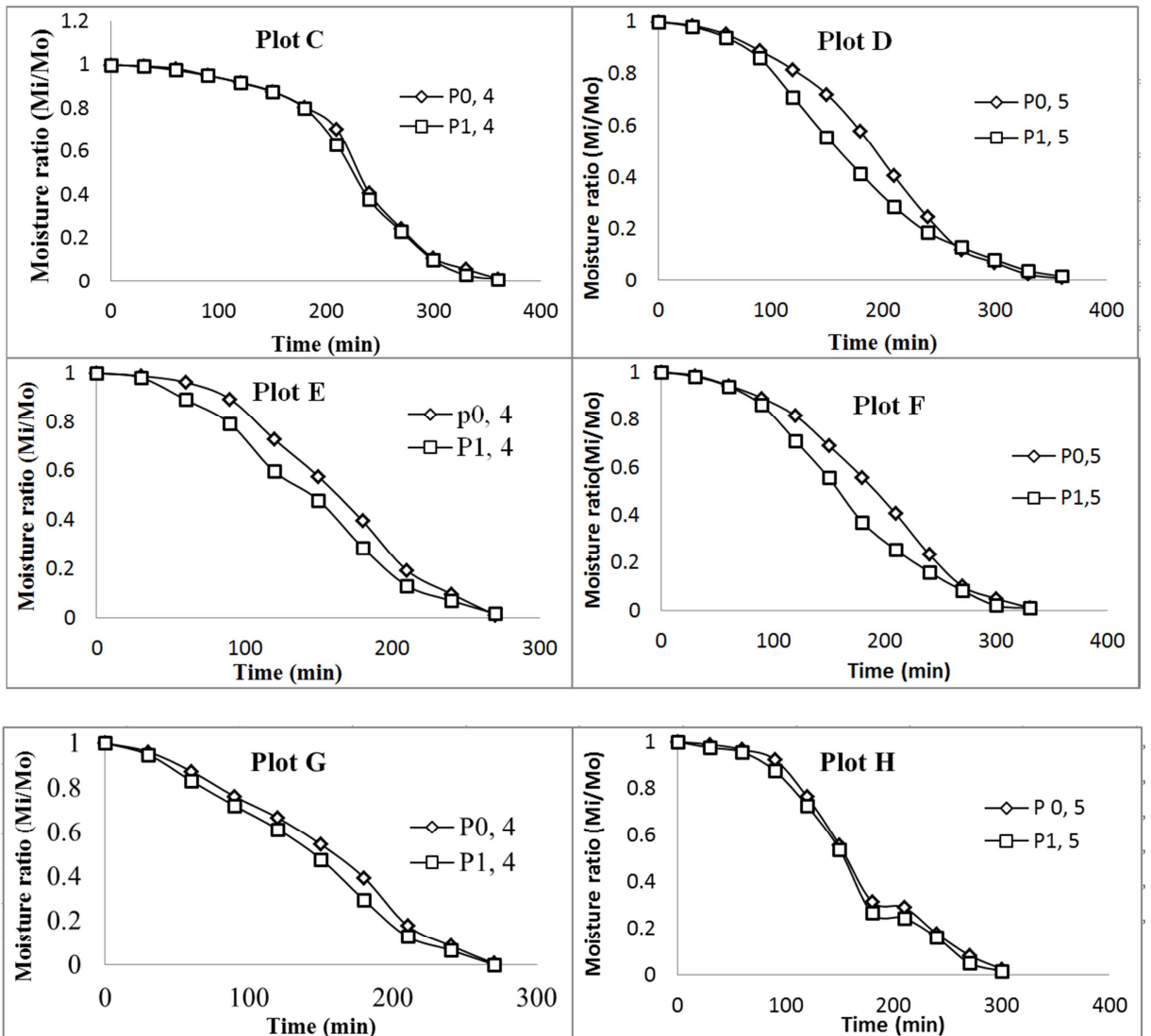

Figure 2. Effect of Sulphite on the Drying Behaviour of Pumpkin Fruit Slices of Thickness $4 \mathrm{~mm}$ (plots A, C and E) and $5 \mathrm{~mm}$ (plots B, D and F) at 70,75 and $80^{\circ} \mathrm{C}$. 
A similar report was obtained by Tatsadjieu et al, who dried a high moisture $(60.08 \%)$ food known as kindumu which is a fermented milk-based sorghum flour product [32]. Longer drying times were observed for the controls compared to the sulphited and the $5 \mathrm{~mm}$ thick compared to the $4 \mathrm{~mm}$ samples. This could be as a result of the influence of sulphite on the cellular membrane of the pumpkin fruit slices. Karim worked on the effect of pre-treatment on quality attributes of air dehydrated pineapple slices and reported a similar observation [33]. The shorter drying times in the $4 \mathrm{~mm}$ thick samples was as a result of increase in surface area due to size reduction [34].

\subsection{Diffusitivity $\left(D_{e f f}\right)$}

The result of $D_{\text {eff }}$ as presented in Table 1 revealed that diffusitivity increased with increase in temperature for all the samples. This was in agreement with Roberts et al who dried three varieties of grape seeds and observed that effective diffusitivity increased with increasing temperature [28]. The diffusitivity values for the $4 \mathrm{~mm}$ slices ranged from $6.235 \times 10^{-11}$ to $1.778 \times 10^{-10} \mathrm{~m}^{2} / \mathrm{s}$ while that of $5 \mathrm{~mm}$ slices ranged from $8.041 \times 10^{-11}$ to $2.189 \times 10^{-10} \mathrm{~m}^{2} / \mathrm{s}$.

Table 1. Effect of Sulphiting on Moisture Diffusitivity of $4 \mathrm{~mm} 5 \mathrm{~mm}$ Thick Pumpkin Fruit Slices.

\begin{tabular}{|c|c|c|c|c|c|c|}
\hline \multicolumn{7}{|c|}{ Diffusitivity $\left(\mathrm{m}^{2} / \mathrm{s} \times 10^{11}\right)$} \\
\hline \multicolumn{3}{|l|}{ Samples } & \multicolumn{4}{|c|}{ Temperatures $\left({ }^{\circ} \mathrm{C}\right)$} \\
\hline Sulphite (\%) & Thickness (mm) & 60 & 65 & 70 & 75 & 80 \\
\hline 0.0 & 4 & 6.235 & 6.928 & 7.505 & 10.643 & 11.205 \\
\hline 1.0 & 4 & 6.928 & 7.505 & 8.256 & 11.462 & 12.808 \\
\hline 0.0 & 5 & 9.046 & 9.742 & 14.070 & 14.071 & 16.890 \\
\hline 2.0 & 5 & 10.550 & 15.350 & 15.421 & 20.890 & 21.330 \\
\hline
\end{tabular}

The determined values of $\mathrm{D}_{\text {eff }}$ for pumpkin fruit slices were in agreement with earlier reports that described the $D_{\text {eff }}$ range for food materials to be from $8.0 \times 10^{-12}$ to $6.46 \times 10^{-9}$ and $10^{-11}$ to $10^{-9}[35,17]$. The control samples were observed to exhibit lower $D_{\text {eff }}$ values than the sulphited samples. This could have been as a result of sulphite pre-treatment which might have affected the permeability of cellular membrane of the slices, creating a faster drying rate at the drying temperatures. This might have resulted in reduction of tensional and firmness of the slices thereby, causing an increase in $\mathrm{D}_{\text {eff }}$ when compared to the control samples. This was also observed in papaya as well as sulphited and oven dried pineapple slices $[36,37]$.

\subsection{Activation Energy}

The activation energy values were estimated from the slopes of straight lines from plotting $\ln \left(\mathrm{D}_{\text {eff }}\right)$ versus $1 / T$. The values of $E_{a}$ for each sample thickness are shown in Table 2.

Table 2. Effect of Sulphiting on Arrhenius Parameters of Pumpkin Fruit Slices.

\begin{tabular}{lllll}
\hline \multirow{2}{*}{ Regression parameter } & Sulphite & Pumpkin & \multicolumn{2}{l}{ Slices } \\
\cline { 2 - 5 } & & 0.0 & 1.0 & 0.0 \\
\hline $\mathrm{n}$ & Thickness $(\mathrm{mm})$ & 4 & 4 & 5 \\
$\mathrm{r}^{2}$ & & 5 & 5 & 5 \\
Intercept & & 0.947 & 0.956 & 5 \\
$\mathrm{~K}_{\mathrm{o}}$ & & 13.07 & 13.50 & 0.974 \\
Slope & & 1.116 & 1.130 & 13.49 \\
$\mathrm{E}_{\mathrm{a}}(\mathrm{KJ} / \mathrm{mol})$ & -3758 & -3872 & 1.116 \\
\hline
\end{tabular}

$\mathrm{n}=$ number of treatments, $\mathrm{r}^{2}=$ coefficient of determination, $\mathrm{k}_{0}=$ reaction rate constant, $\mathrm{E}_{\mathrm{a}}=$ activation energy.

It was observed that the activation energy values increased with increasing slice thickness, showing the sensitivity of $D_{\text {eff }}$ values to the slice thickness, i.e. the higher the activation energy, the higher the effect of sample thickness on $D_{\text {eff }}$ values. $E_{a}$ values for $4 \mathrm{~mm}$ slices were 31.342 and $32.293 \mathrm{~kJ} / \mathrm{mol}$ for P0, 4 and P1, 4 respectively, while that of $5 \mathrm{~mm}$ slices were 31.525 and $29.882 \mathrm{~kJ} / \mathrm{mol}$ for P0, 5 and P2, 5 respectively. These ranges fall within the general range of (15-40 kJ/mol) for food materials as reported by $[38,41]$.

\subsection{Estimation of Drying Time}

Drying time prediction based on Ficks second law of diffusion Table 3 showed that drying process was faster for the sulphited samples compared to their controls.

Table 3. Effect of Sulphiting and Slice Thickness on Drying Time of Pumpkin Fruit Slices.

\begin{tabular}{lllllll}
\hline \multicolumn{2}{l}{ Sample Drying Air Conditions Drying Time } & & & \\
\hline Code & Sulphiting (\%) & Thickness (mm) & Temp. $\left({ }^{\circ} \mathbf{C}\right)$ & Velocity (m/s) & RH (\%) & (hr) \\
\hline P, 4 & 0 & 4 & 75 & 1.52 & 32 & 16.5 \\
P1, & 1 & 4 & 75 & 1.52 & 32 & 15.2 \\
\hline
\end{tabular}




\begin{tabular}{lllllll}
\hline \multicolumn{2}{l}{ Sample Drying Air Conditions Drying Time } & & & \\
\hline Code & Sulphiting (\%) & Thickness $(\mathbf{m m})$ & Temp. $\left({ }^{\circ} \mathbf{C}\right)$ & Velocity (m/s) & RH (\%) & (hr) \\
\hline P0, 5 & 0 & 5 & 75 & 1.52 & 32 & 17.8 \\
P2, 5 & 2 & 75 & .52 & 32 & 16.9 \\
\hline
\end{tabular}

P0, 4=Non sulphited pumpkin fruit slices of $4 \mathrm{~mm}, \mathrm{P} 1,4=$-Pumpkin fruit slices of $4 \mathrm{~mm}$ thickness, $1 \%$ sulphited, P0, $5=$ Non sulphited pumpkin fruit slices of $5 \mathrm{~mm}$ thickness, P2, $5=$ Pumpkin fruit slices of $5 \mathrm{~mm}$ thickness, $2 \%$ sulphited.

The $5 \mathrm{~mm}$ thick sample took a longer time $(16.9 \mathrm{~h})$ to dry compared to the $4 \mathrm{~mm}$ sample $(15.2 \mathrm{~h})$. This implies that sample thickness had noticeable effect probably for the fact that drying of the sample took place in the falling rate period indicating that the mechanism of diffusion is governed by internal diffusion where the distant travelled by the diffusing vapour (thickness) becomes a controlling factor. The estimated drying time was higher than the experimental drying time for each of the sample thicknesses. This could be as a result of the fact that Ficks law of diffusion is based on assumptions which in practice do not hold, for instance, the model assumes negligible external resistance however, an air velocity of greater than $1 \mathrm{~m} / \mathrm{s}$ has significant influence on drying [39].

\subsection{Rehydration Capacity}

Result of rehydration as presented in Table 4, showed that, the control samples rehydrated better than the sulphited samples at all the temperatures tested $\left(30,60\right.$ and $\left.80^{\circ} \mathrm{C}\right)$. The $4 \mathrm{~mm}$ thick samples rehydrated better than the $5 \mathrm{~mm}$ thick samples. The $4 \mathrm{~mm}$ samples rehydrated best at $60^{\circ} \mathrm{C}$ followed by $30^{\circ} \mathrm{C}$ and least at $80^{\circ} \mathrm{C}$. While the $5 \mathrm{~mm}$ samples rehydrated best at $30^{\circ} \mathrm{C}$ followed $60^{\circ} \mathrm{C}$ and the least rehydration ratio was observed at $80^{\circ} \mathrm{C}$. It then implies that, the $4 \mathrm{~mm}$ samples can be rehydrated at $60^{\circ} \mathrm{C}$ while the $5 \mathrm{~mm}$ at $30^{\circ} \mathrm{C}$. The $5 \mathrm{~mm}$ sample took a longer time to dry to its equilibrium moisture content and demonstrated lower rehydration ratios. Literature report revealed that the rehydration ratios of apple, potato, carrot, banana, pepper, garlic and mushroom range between 1 and 4 , depending on the absorbed water temperature [40].

Table 4. Effect of Sulphiting and Slice Thickness on Rehydration Capacity of Dried Pumpkin Fruit Slices.

\begin{tabular}{llll}
\hline Sample & \multicolumn{3}{l}{ Temperature $\left({ }^{\circ} \mathbf{C}\right)$} \\
\hline & $\mathbf{3 0}$ & $\mathbf{6 0}$ & $\mathbf{8 0}$ \\
\hline P1, 4 & $3.72^{\text {cd }} \pm 0.03$ & $3.98^{\mathrm{a}} \pm 0.00$ & $3.50^{\mathrm{b}} \pm 0.03$ \\
P0, 4 & $3.94^{\mathrm{a}} \pm 0.03$ & $3.97^{\mathrm{b}} \pm 0.01$ & $3.78^{\mathrm{a}} \pm 0.01$ \\
$\mathrm{P} 2,5$ & $3.44^{\mathrm{e}} \pm 0.02$ & $3.14^{\mathrm{e}} \pm 0.01$ & $3.36^{\mathrm{d}} \pm 0.02$ \\
P0, 5 & $3.62^{\mathrm{d}} \pm 0.02$ & $3.20^{\mathrm{d}} \pm 0.01$ & $3.28^{\mathrm{e}} \pm 0.03$ \\
LSD & 0.03 & 0.01 & 0.03 \\
\hline
\end{tabular}

Values are means of triplicate determinations. Values with the same superscripts are not significantly different at $\mathrm{P}<0.05$.. $\mathrm{P} 0,4=$ Non sulphited pumpkin fruit slices of $4 \mathrm{~mm}, \mathrm{P} 1,4-=$ Pumpkin fruit slices of $4 \mathrm{~mm}$ thickness, $1 \%$ sulphited, $\mathrm{P} 0,5=$ Non sulphited pumpkin fruit slices of $5 \mathrm{~mm}$ thickness, P2, 5=Pumpkin fruit slices of $5 \mathrm{~mm}$ thickness, $2 \%$ sulphited.

In this study, sulphited and dry pumpkin fruit slices had a rehydration ratio range of 3.14-3.98 at absorbed water temperatures of 30,60 and $80^{\circ} \mathrm{C}$ which is within the reported range. It can therefore be inferred that the rehydration ratio of sulphited and dried pumpkin fruit slices was influenced by rehydration temperature, pretreatment and sample thickness. This is in agreement with the report of Dhalsamant et al where rehydration ability of solar dried potato was significantly influenced by pretreatment followed by rehydration temperature and sample diameter [41].

\section{Conclusion}

Influence of sulphite on the drying kinetics of pumpkin revealed that, drying of sulphited pumpkin fruit slices occurred mainly in the falling rate period which is typical of the drying behaviour of food products. Diffusitivity increased with increase in sulphite level and drying temperature for the $4 \mathrm{~mm}$ and $5 \mathrm{~mm}$ thick slices. Slice thickness also influenced the activation energy of pumpkin fruits slices. This implies that the internal transfer of moisture in the sulphited pumpkin slices was controlled by moisture diffusion and this is important in food packaging and storage where transfer of moisture, vapours (gases) and flavour compounds may adversely influence food quality. Sulphite enhanced reduced drying time of fresh pumpkin fruit slices as well as slice thickness. It can be inferred that drying time reductions in the drying process of fresh pumpkin fruit slices will definitely amount to significant energy savings since hot air drying processes do have intensive energy requirement. Based on the result of the reconstitution of dried pumpkin fruit slices, it can be deduced that, the non sulphited slices can be rehydrated better at room temperature $\left(30^{\circ} \mathrm{C}\right)$ whereas the sulphited sample slices reconstitute better at temperatures higher than room temperature.

\section{References}

[1] Adekpoju, G. K. A. and Adebanjo, A. A. (2011): Effect of Consumption of Cucurbita pepo Seeds on the Haematological and Biochemical Parameters. African Journal of Pharmacy and Pharmacology, 5 (1) 18-22.

[2] Chonoko, U. G. and Rufai, A. B. (2011) Phytochemical Screening and Antibacterial Activity of Cucurbita pepo (Pumpkin) Against Staphiloccocus aureus and Salmonella typhi: Bayero Journal of Pure and Applied Sciences, 4 (1); 145-147.

[3] Dehghannya, J., Hossienlar, S. and Heshmati, M. K. (2018). Multi-stage continuous and intermittent microwave drying of quince fruit coupled with osmotic dehydration and low temperature hot air drying. Innovative Food Science and Engineering Technologies, 45: 132-151.

[4] Azizah, A. H., Wee, K. C., Azizah, O. and Azizah, M. (2009). Effect of boiling on total phenolics, carotenoids and radical scavenging activity of pumpkin (Cucurbita moschato). International Food Research Journal, 16, 45-51. 
[5] Al-Ghazal, A. T. (2012). Evaluation of antibacterialeffect of Cucurbita pepo (Yakten) extracts on multi-antibiotic resistance strains isolated from human urinary tract infections. Raf. Journal of Science, 23 (1) 1-7.

[6] Azevedo-Meleiro, C. H. and Rodriguez-Amaya, D. B. (2007): Qualitative and quantitative differences in Carotenoids Composition among Cucurbita moschata, Cucurbita maxima, and Cucurbita pepo. Journal of Agriculture and Food C hemistry, 55, 4027-4033.

[7] Markovic M, Mülleder U, Neunteufl H. (2002). Carotenoid content in different varieties of pumpkins. Journal of Food Composition Analysis; 15: 633-638.

[8] Smith, P. G. (2011). Introduction to Food Process Engineering. 2nd edition, Springer New York Dordrecht Heidelberg London.

[9] Seremet, L., Botez, E., Nistor, O.-V., Andronoiu, D. G., \& Mocanu, G.-D. (2016). Effect of different drying methods on moisture ratio and rehydration of pumpkin slices. of Food Chemistry, 195, 104-109.

[10] Gujral, H. S.; Oberoi, D. P. S.; Singh, R. and Gera, M. (2013): Moisture Diffusivity during Drying of Pineapple and Mango Leather as Affected by Sucrose, Pectin and Maltodextrin. International Journal of Food Properties, 16: 359-368.

[11] Ramallo, L. A., and Mascheroni, R. H. (2012). Quality evaluation of pineapple fruit during drying process. Food and Bioproducts Processing, 90: 275-283.

[12] Zhao D., An, K., Ding, S., Liu, L., Xu, Z., \& Wang, Z. (2014). Two-stage intermittent microwave coupled with hot-air drying of carrot slices: Drying kinetics and physical quality. Food and Bioprocess Technology, 7 (8), 2308-2318.

[13] Aghilinategh, N., Rafiee, S., Gholikhani, A., Hosseinpur, S., Omid, M., Mohtasebi, S. S. and Maleki, N. (2015). A comparative study of dried apple using HA, intermittent and continuous microwave: Evaluation of kinetic parameters and physicochemical quality attributes. Journal of Food Science and Nutrition, 3 (6), 519-526.

[14] Vázquez-Vila, M. J., Chenlo-Romero2, F. Moreira-Martínez2, R. and Pacios Penelas, B. (2009). Dehydration kinetics of carrots (Daucus carota L.) in osmotic and air convective drying processes. Spanish Journal of Agricultural Research, 7 (4), 869-875.

[15] Prajapati, V. K., Nema, P. K. and Rathore, S. S. (2011). Effect of pretreatment and drying methods on quality of value-added dried aonla (Emblica officinalis Gaertn) shreds. Journal of Food Science and Technology, 48 (1): 45-52.

[16] Nguyen, M. H and Price W. E (2007). Air-drying of banana: Influence of experimental parameters, Slab thickness, banana maturity and harvesting season. Journal of FoodEngineering, 78, 200-207.

[17] Doymaz, I. (2007A). Convective Drying Kinetics of Strawberry. Foods and Food Components. Lebensmittel.-Wiss Technologie, 9: 107-113.

[18] Limpaiboon, K and Wiriyaumpaiwong, S. (2009): Drying kinetics of steamed glutinous rice by free convective solar dryer. Walailak Journal of Science and Technology, 6, 217229.
[19] Apati, G. P., Furlan, S. A., and Laurindo, J. B. (2010). Drying and rehydration of oyster mushroom. Braz. Arch. Biol. Technol., 53 (4): 945-952.

[20] Jindarat, W., Sungsoontorn, S., \& Rattanadecho, P. (2015). Analysis of energy consumption in a combined microwavehot air spouted bed drying of biomaterial: Coffee beans. Journal of Experimental Heat Transfer, 28 (2), 107-124.

[21] Le, T. Q. and Jittanit, W. (2015). Optimization of operating process parameters for instant brown rice production with microwave-followed by convective hot air drying Journal of Stored Products Research, 61, 1-8.

[22] Kowalski, S. J., Szadzińska, J., \& Łechtańska, J. (2013). Nonstationary drying of carrot: Effect on product quality. Journal of Food Engineering, 118 (4), 393-399.

[23] Tzempelikos, D. A., Vouros, A. P., Bardakas, A. V., Filios, A. E., \& Margaris, D. P. (2014). Case studies on the effect of the air drying conditions on the convective drying of quinces. Case Studies in Thermal Engineering, 3, 79-85.

[24] Limpaiboon, K. (2011) Effects of Temperature and Slice Thickness on Drying Kinetics of Pumpkin Slices. Walailak Journal of Science and Technology, 8 (2) 159-166.

[25] Artnaseaw, A., Theerakulpisut, S., and Benjapiyaporn, C. (2010). Drying characteristics of Shiitake mushroom and Jindachilli during vacuum heat pump drying. Food Bioprod. Process, , 88: 105-114

[26] Jittanit, W. (2011). Kinetics and temperature dependent moisture diffusitivities of pumpkin seeds during drying. Kasetsart University Journal of Natural Science, 45: 147-158.

[27] Arumuganathan, T., Manikantan, M. R., Rai, R. D. Anandakumar, S., and Khare, V. (2009). Mathematical modeling of drying kinetics of milky mushroom in a fluidized bed dryer. International Journal of Agrophys., 23: 1-7.

[28] Roberts, J. S., Kidd, D. R. and Padilla-Zakour, O. (2008). Drying kinetics of grape seeds. Journal of Food Engineering, 89 (4): 460-465.

[29] Serap, K. and Ertekin, C. (2011). Vacuum drying Kinetics of barbunya bea (Phaseolus vulgaris L. Elipticus Mart.). The Philippine Agricultural Scientist Vol. 94 No.3, 285-291.

[30] Doymaz, I., Demir, H., \& Yildirim, A. (2015). Drying of quince slices: Effect of pretreatments on drying and rehydration characteristics. Journal of Chemical Engineering and Communications, 202 (10), 1271-1279.

[31] Akbarian, M., Ghanbarzadeh, B., Sowti, M., \& Dehghannya, J. (2014). Effects of pectin-CMC-based coating and osmotic dehydration pretreatments on microstructure and texture of the hot-air dried quince slices. Journal of Food Processing and Preservation, 39, 260-269.

[32] Tatsadjieu N. L.; Etoa F. X.; Mbofung C. M. F. (2004). Drying Kinetics, Physico-Chemical anNutritional Characteristics of 'Kindimu', a fermented milk based Sorghum Flour. Journal of food Techology in Africa.

[33] Karim OR, Sanni LO and SO Awonorin (2008) Effect of pretreatments on quality attributes of air-dehydrated pineapple slices. Journal of Food Technology; 6 (45): 154-165.

[34] Doymaz, I. (2007a). The kinetics of forced convective air drying of pumpkin slices. Journal of Food Engineering, 79, 243-248. 
[35] Lertworasirikul S. (2007). Drying kinetics of semi-finished cassava crackers: A comparative study. Lebensmittel-Wiss and Technologie- Food Science and Technology 41, 1360-1371.

[36] Kraipat Cheenkachorn, Piyawat Jintanatham, Sarun Rattanaprapa (2012). Drying of Papaya (Carica papaya L.) using a Microwave-vacuum Dryer. World Academy of Science, Engineering and Technology Vol: 6, 09-27

[37] Karim, O. R. (2010). Effects of sulphiting and osmotic pretreatments on the effectivemoisture diffusion coefficients $\left(\mathrm{D}_{\mathrm{ff}}\right)$ of air drying of pineapple slices. Journal of Food Technology; 10 (10): 4163-4184.

[38] Rizvi, S. S. H. (2005). Thermodynamic properties of foods in dehydration. In: Rao M. A.; Rizvi, S. S. H. (3 ${ }^{\text {rd }}$ Eds). Engieering properties of foods. Macel, Delder Inc. New York. Pp238-326.
[39] Sankat, C. K.; Castaigne, F.; Maharaj, R. (1996) The air drying behavior of fresh and Osmotically dehydrated banana slices. International Journal of Food Science and Technology, 31, 123-135.

[40] Krokida MK, Marinos-Kouris D. (2003) Rehydration Kinetics of Dehydrated Products. Journal of Food Engineering; 57 (1) $1-7$.

[41] Dhalsamant, K., Punyadarshini P. T. and Shrivastava, S. L (2017). Effect of pre-treatment on rehydration, colour and nano indentation properties of potato cylinders dried using a mixed-mode solar dryer. Journal of Food Science and Agriculture. 97, 3312-3322. 